\title{
La llegada de un nuevo entretenimiento. Circulación y apropiación del cine silente norteamericano en Colombia, 1910-1929
}

Resumen: Este artículo analiza las modalidades comerciales y culturales bajo las cuales el cine silente norteamericano ingresó a Colombia y desplazó gradualmente los gustos cinematográficos de Europa hacia los Estados Unidos a finales de 1920. Así, expone cómo las productoras de cine norteamericanas trataron de comprender las necesidades comerciales de distribuidores y exhibidores de cine en Colombia y cómo se esforzaron por complacer los gustos cinematográficos del público al tiempo que los estandarizaban. Por medio del análisis de correspondencia consular norteamericana, revistas de cine y registros de prensa, a nivel local e internacional, se subraya, además, aspectos de la modernidad cultural y del intercambio comercial entre Colombia y Estados Unidos a principios del siglo XX.

Palabras clave: historia del cine, circulación y apropiación de películas, gustos fílmicos, americanización cultural.

\section{The arrival of a new entertainment. Circulation and appropriation of the American Silent Cinema in Colombia, 1910-1929}

Abstract: This article analyses the commercial and cultural modalities which made possible the entrance of American silent cinema in Colombia and the displacement of local tastes for European cinema towards US cinema at the end of 1920. It exposes the ways in which American studios sought to understand the commercial needs of film distributors and exhibitors in Colombia and to please and standardize taste. Through the analysis of American consular correspondence, film magazines, and local and international press records, this article highlights aspects of cultural modernity and of the commercial exchange between Colombia and the United States at the beginning of the 20th century.

Keywords: history of cinema, circulation and appropriation of films, film tastes, cultural americanization.

\section{A entrada de um novo entretenimento. Circulação e apropriação do cinema mudo americano na Colômbia, 1910-1929}

Resumo: Este artigo analisa as modalidades comerciais e culturais sob as quais o cinema mudo americano entrou na Colômbia e gradualmente deslocou os gostos cinematográficos da Europa para os Estados Unidos no final de 1920. Assim, expõe como a American Studios tentou entender as necessidades comerciais dos distribuidores de filmes e expositores de filmes na Colômbia. E ainda, como tentaram agradar aos gostos dos cinéfilos, enquanto os padronizavam. Através da análise da correspondência consular americana, revistas de cinema e registros imprensa local e internacionalmente, este artigo também destaca os aspectos da modernidade cultural e do intercâmbio comercial entre a Colômbia e os Estados Unidos no início do século XX.

Palavras-chave: história do cinema, comércio de filmes, gostos de cinema, americanização.

Cómo citar este artículo: Leidy Paola Bolaños Florido, "La llegada de un nuevo entretenimiento. Circulación y apropiación del cine silente norteamericano en Colombia, 1910-1929”, Trashumante. Revista Americana de Historia Social 14 [2019]: 76-98.

DOI: 10.17533/udea.trahs.n14a04

Fecha de recepción: 24 de abril de 2018

Fecha de aprobación: 5 de noviembre de 2018

Leidy Paola Bolaños Florido: Doctora en Historia por la Universidad de los Andes [Colombia].

Correo electrónico: Ip.bolanos147@uniandes.edu.co 


\section{La llegada de un nuevo entretenimiento. Circulación y apropiación del cine silente norteamericano en Colombia, 1910-1929}

Leidy Paola Bolaños Florido

\section{Introducción}

a circulación del cine en Colombia durante la época del cine silente estuvo Luertemente influida por la competencia a escala global entre Europa y Estados Unidos - como dos industrias filmicas potentes en las primeras décadas del siglo XX - y por las dinámicas de la distribución y exhibición de cine en varias zonas urbanas de Colombia, en las cuales tuvieron peso las dos únicas compañías distribuidoras cinematográficas existentes durante este período. Por un lado, están los hermanos Di Doménico que provenían de una familia italiana dedicada al comercio ambulante de mercancías y que antes de formalizar la firma distribuidora y exhibidora de películas Di Doménico Hermanos y Cía. en 1912, ya habían traído al país los primeros cortometrajes extranjeros para su exhibición ambulante. Por otro lado, está el caso del empresario de cine colombiano Belisario Díaz, que en 1913 formó la Empresa Nacional de Kinematógrafos Universal, también conocida como "Kine Universal". Díaz había sido promotor de boxeo y toros, y pasó a la exhibición de películas prácticamente por cuestiones de azar al comprar un aparato de proyección Pathé en Panamá a un exhibidor ambulante. Estas dos firmas cumplían la función de mediar entre la industria fílmica europea y la norteamericana a las que compraban las películas que se adaptaban mejor a las preferencias del público y a sus lógicas económicas.

El abastecimiento de un mercado regular de películas norteamericanas en Colombia también fue posible por la labor de los agentes consulares ubicados en Latinoamérica, quienes bajo las órdenes del Departamento de Estado y el Departamento de Comercio de Washington se encargaban de fungir como intermediarios entre las dos empresas de cine local y los productores filmicos estadounidenses. Como lo han puesto de presente otros estudios, el Departamento de Estado de Estados Unidos y los cónsules norteamericanos residentes en América Latina fueron los encargados de filtrar, a partir de 1916, la información sobre el estado del 
cine a escala internacional para traspasarla a las productoras y distribuidoras de cine norteamericanas. ${ }^{1}$

Este trabajo también se fija en otros actores del proceso de difusión y apropiación del cine comercial como los cronistas, corresponsales y aquellos que promocionaron las películas y difundieron sus opiniones y comentarios — no exentos de prejuicios y valoraciones - respecto a las películas y al comportamiento del público en el cine. Ellos fueron el enlace entre la triada formada por la industria editorial y cinematográfica norteamericana, las firmas de exhibición local y los espectadores colombianos. ${ }^{2}$

Esa cooperación, no exenta de dificultades, entre agentes locales y extranjeros contribuyó a delinear el proceso de despegue de la actividad cinematográfica en Colombia, caracterizada por la ausencia de una fuerte producción fílmica nacional y por el dominio compartido de las pantallas de cine de Estados Unidos y Europa. ${ }^{3}$ La investigación de Emily Rosenberg estima que en 1925 "las películas norteamericanas comprendieron aproximadamente el 95\% del total de películas vistas en Gran Bretaña y Canadá, 70\% en Francia y 80\% en Sudamérica". El informe estadístico de 1927 elaborado por la Oficina de Comercio de Estados Unidos, además anotaba que el cine francés era el próximo en popularidad en América Latina. Con respecto a la producción nacional, el reporte puntualizaba que "no hay producción local de qué hablar"; Argentina se destacó al producir alrededor de veinte películas en 1925, mientras Brasil y Chile mantuvieron un número aún más reducido de producción fílmica silente por lo que, generalmente, la producción nacional latinoamericana no fue considerada como competitiva de la industria hollywoodense. ${ }^{5}$ En 1935, el 95\% de películas importadas a Colombia tenían el sello norteamericano, ${ }^{6}$ y en la década anterior esas producciones ya habían alcanzado una elevada tasa de exportación a países como Argentina, Brasil,

1. Al respecto, véase Emily Rosenberg, Spreading the American Dream. American Economic and Cultural Expansion, 1890-1945 (New York: Hill and Wang, 1982); Seth Fein, "El cine y las relaciones culturales entre México y Estados Unidos durante la década de 1930", Secuencia. Revista de historia y ciencias sociales 34 (1996): 155-196; Fernando Purcell, "Una mercancía irresistible. El cine norteamericano y su impacto en Chile, 1910-1930”, Historia Crítica 38 (2009): 46-69.

2. El testimonio de estos intermediarios de la circulación y la difusión del cine constituyó una de las principales vías para aproximarnos a las impresiones y opiniones que dejó el cine silente en el público, en particular, sobre aquel que no siempre podía acceder a la escritura y a los medios impresos.

3. En Colombia no hubo una industria filmica nacional lo suficientemente fuerte para hacer contrapeso a la importación de películas europeas y norteamericanas. Entre 1920 y 1930, por ejemplo, solo hubo 9 películas silentes. Acerca del cine nacional véase Álvaro Concha Henao, Historia social del cine en Colombia, t. 1 (Bogotá: Publicaciones Black María Escuela de Cine, 2014).

4. Rosenberg 100-101. La traducción de todos los textos en inglés, incluidas las fuentes manuscritas, fue hecha por la autora.

5. "Latin America", Film Daily Year Book (New York) 1927: 957.

6. El porcentaje restante proviene principalmente de México.Whintrop C. Cremer a Filmarte Theatre Corporation, "Carta de Cónsul de Bogotá", Bogotá, 7 de junio de 1935. NARA, College Park, RG 84, Colombia Diplomatic Post, vol. 88, s.f. 
México, Cuba y Chile, con lo que se desplazaba de manera contundente a las películas europeas. ${ }^{7}$

A diferencia del caso colombiano, ya a finales de la década de 1910, en estos países latinoamericanos había representantes directos de las grandes compañías norteamericanas: Fox, Paramount, Universal, United Artists, que manejaban ampliamente el negocio de la distribución y exhibición de películas. Por un lado, esto significó la pérdida de la autonomía comercial de los empresarios de cine locales, quienes quedaron supeditados al control de magnates norteamericanos que controlaban la mayor parte del negocio cinematográfico. Por otro lado, se convirtió en una muestra evidente de modernización cinematográfica que destacó a estos países en el mundo del cine silente; de esta manera, se construyeron numerosas y sofisticadas salas de cine y circuló un repertorio de películas hollywoodenses más amplio y actualizado. ${ }^{8}$

Debido a ello es que en el período del cine silente Hollywood no debe verse como un mercado ya formado que se impuso sobre otros, sino como un proceso en marcha. Era más bien una industria en ascenso que, así como tuvo rápida aceptación en los mercados extranjeros, también tuvo obstáculos comerciales relacionados, por ejemplo, con el enorme peso de la industria filmica europea en los mercados de exportación mundiales, con las particularidades de cada país consumidor de películas y, sobre todo, con los gustos artísticos del público y con los complejos circuitos locales de distribución y exhibición local en numerosas partes del mundo.

No se trata de desconocer que la "americanización" a través del cine está atravesada por una desigual distribución de poder y que Estados Unidos, a diferencia de otros mercados cinematográficos, tuvo en las décadas de 1910 y 1920 aspiraciones expansionistas al querer llevar sus películas a vastas áreas geográficas. ${ }^{9}$ Sin embargo, es necesario considerar que durante ese tiempo este país estaba forjándose como una industria que intentaba hacer contrapeso a la industria filmica europea, la cual hasta 1920 gozó de una prosperidad cinematográfica a pesar de la guerra. Para lograrlo, Estados Unidos necesitó atraer a empresarios cinematográficos y

7. “American Film Exports Increasing”, The International Photographer (New York) diciembre de 1930: 8; "Distribution of Motion Picture Theatre", Exhibitors Herald (Chicago) 8 de febrero de 1930: 31.

8. Al respecto, véase Loius Pérez, On Becoming Cuban. Identity, Nationality and Culture (Chapel Hill: University of North Carolina Press, 1999) 279-313; Laura Serna, Making Cinelandia. American Films and Mexican Film Culture before the Golden Age (Durham: Duke University Press, 2014); Fernando Purcell, ;De Película! Hollywood y su impacto en Chile, 1910-1950 (Santiago:Taurus, 2012); Camila Gatica, "Social Practices of Modernity: Cinema-going in Buenos Aires and Santiago, 1915-1945" (Tesis de doctorado en Historia, University College London, 2013).

9. Aquí se entiende "americanización" cinematográfica como el gusto por la vida material, tecnológica y cultural de Estados Unidos evidenciada en las películas y sus estrellas. Es posible que la fuerza de la Americanization a través del cine resida, sobre todo, en el empeño de Estados Unidos por acaparar el talento y la creatividad de otros países y "reinventarlos" para difundirlos a la manera norteamericana. Carlos Monsiváis, “¿Cómo se dice OK en inglés?”, La americanización de la modernidad, comp. Bolívar Echeverría (México: Era, 2008) 97-120. 
espectadores extranjeros y trató de comprender sus aptitudes, sus gustos y sensibilidades a partir de un vasto conglomerado de agentes e instituciones. ${ }^{10}$

Este artículo muestra algunas de las formas a través de las cuales Hollywood ingresó a Colombia y desplazó gradualmente las preferencias comerciales y los gustos cinematográficos de los colombianos de Europa hacia Estados Unidos durante los años del cine silente. Es un período que no responde a una época "preindustrial" del cine, sino a un momento en el cual se edificaron las bases del espectáculo del cine como entretenimiento de masas. Para tratar de sustentar los objetivos propuestos, el artículo muestra algunos de los obstáculos comerciales y culturales que tuvo el mercado de Hollywood para alcanzar popularidad en las décadas de 1910 y 1920 en Colombia, entre ellos, la negativa de comprar películas norteamericanas por parte de los empresarios locales y la negativa de los espectadores de consumir películas viejas o de "segunda mano" provenientes de Estados Unidos, así como su resistencia a ver contenidos filmicos demasiado "crudos" y "realistas" o que exaltaban los símbolos patrios de ese país.

Posteriormente, el texto muestra cómo las series de cine de crímenes y aventuras — que habían perdido su popularidad en Estados Unidos en 1915- desplazaron paulatinamente los gustos cinematográficos de los colombianos de Europa a Estados Unidos a finales de la década de 1910 y a principios de los años 1920. De ello sacarían provecho los empresarios de cine colombianos que, gradualmente, dejaron de comprar películas a Europa para continuar con la compra de estas series basadas en literatura popular y en la novela folletín. El propósito era satisfacer los gustos del público mayoritario y seguir con la difícil empresa de formar un mercado de cine fijo y regular y, en grado considerable, independiente de otros divertimientos, en un país donde el teatro no era un hábito para la mayor parte de la población y donde recién se estaba preparando el terreno para el disfrute cultural y la aceptación del más grande entretenimiento de la primera mitad del siglo XX: la industria del cine.

Esto último cobra importancia en la historia de las circulaciones y las apropiaciones de medios de bienes de consumo materiales y simbólicos y en objetos transnacionales como las películas, si atendemos a la maleabilidad de aquellos para transportarse de un lugar a otro y transformarse localmente a partir de sus migraciones y adaptaciones. Asimismo, tomar en cuenta el papel activo de los diversos agentes que participan en el proceso de circulación, difusión y recepción de un objeto o actividad cultural. ${ }^{11}$

10. Sobre este punto, véase Purcell, ;De película! 76 y 77.

11. Al respecto, véase Roger Chartier, Cardenio entre Cervantes y Shakespeare. Historia de una obra perdida (Barcelona: Gedisa, 2012); Lawrence Levine, The Emergence of Cultural Hierarchy in America (Cambridge: Harvard University Press, 1988). Sobre los movimientos transnacionales entre Estados Unidos y Latinoamérica sustentados menos en la coerción y la dominación y mucho más en las formas de seducción, la cooperación y la resignificación en términos locales, para el caso del cine hollywoodense, véase, por ejemplo, Hiroshi Kitamura, Screening Enlightenment. Hollywood and the Cultural Reconstruction of Defeated Japan (Ithaca / Londres: Cornell University Press, 2010); Purcell, iDe Película!; Serna. 
La información sobre la que aquí reflexiono fue recabada de artículos de prensa extranjera y local que circularon entre 1910 y 1920 y, principalmente, de la correspondencia consular entre el Departamento del Estado en Washington, los empresarios filmicos y las embajadas estadounidenses que se encuentran en National Archives and Records Administration (NARA). Estos archivos corresponden, principalmente, a Cartagena, Barranquilla, Bogotá, Cali, Medellín y Buenaventura como ciudades que en el primer tercio del siglo XX se destacaron, entre otros espacios urbanos, por concentrar la mayor población y por convertirse en el foco del desarrollo agroindustrial y cafetero. De igual manera, Barranquilla, Cartagena y Buenaventura ocuparon un lugar importante en el desarrollo comercial por ser puertos fluviales y marítimos que vinculaban al país con el comercio internacional. Estas fueron, de hecho, las primeras ciudades donde se instalaron los consulados norteamericanos y se abrió la actividad del cine en el país. El despunte de la urbanización, ${ }^{12}$ el auge de las obras públicas, la instalación de luz eléctrica y la mano de obra asalariada en la segunda década del siglo XX estimularon la apertura de salas de cine permanentes, como estaba ocurriendo en varias ciudades latinoamericanas. ${ }^{13}$

\section{El cine como campo cultural incipiente a principios del siglo XX}

En las décadas de 1910 y 1920 , pese a algunos avances concernientes a la modernización cultural de Colombia, algunos agentes consulares estadounidenses no lograban ver a este país como un terreno fértil en el ámbito de los divertimentos públicos, lo que seguramente desanimaba a las compañías extranjeras a invertir en entretenimientos culturales. Resulta ilustrativo el caso de un cónsul de Barranquilla que le recomendó a un empresario de espectáculos estadounidense, interesado en rentar un teatro en la ciudad, que contactase a sus propietarios, pero antes le advirtió que debía tener cuidado de no llevar cualquier organización teatral a Barranquilla si deseaba obtener ganancias. "Se sabe que recientemente un grupo de activos ciudadanos trabajaron para traer al señor Fleta a Barranquilla, y a pesar del interés y la buena publicidad, este grupo sufrió pérdidas financieras para la empresa". ${ }^{14}$

Estas impresiones sobre Colombia como campo de divertimento cultural infructuoso no solo provenían de los diplomáticos norteamericanos, sino de otros

12. El estudio de Ángela Núñez señala que entre 1925 y 1930 la población urbana creció en un 24\%. Luz Ángela Núñez, El obrero ilustrado. Prensa obrera y popular en Colombia 1909-1929 (Bogotá:Ediciones Uniandes, 2006) 26. Sobre algunas transformaciones económicas y sociales importantes que trazaba la conversión de pueblos grandes en ciudades en el segundo y tercer decenio del siglo XX, véase Ricardo Arias Trujillo, Historia de Colombia contemporánea (1920-2010) (Bogotá: Ediciones Uniandes, 2010).

13. El primer cine fijo fue el Salón Olympia, inaugurado en Bogotá en 1912; al respecto véase Jorge Nieto y Diego Rojas, Tiempos del Olympia (Bogotá: Fundación Patrimonio Fílmico Colombiano, 1992).

14. Fletcher Warren, “Carta del cónsul norteamericano de Barranquilla a Mr. I. S. Nochter", Barranquilla, 5 de abril de 1930. NARA, College Park, RG 84, Colombia Consular Post, vol. 218, s.f. 
observadores de la época. Así, en 1923, un corresponsal de Colombia para Cine Mundial confesó su expectativa de que a Colombia llegara el circo Saenz Freres, aunque consideraba que su temporada debía ser corta en el país, pues "en estas tierras para que un espectáculo distinto al cinematógrafo resulte, se necesita que sea muy completo, y muy bueno". ${ }^{15}$ En 1915, Francisco Montero, corresponsal de The Moving Picture World, señalaba que en este continente los cines podrían ser tan numerosos como en Estados Unidos, en tanto no hay compañías dramáticas u óperas, o espectáculos de vodevil residentes y regulares, “de modo que las ciudades dependen para su diversión de compañías itinerantes ocasionales que pasan a través de su territorio en tiempos programados. La única diversión constante y seria es el espectáculo del cine, y debido a su bajo precio resultaría muy popular, ya que sería frecuentada por ricos y pobres por igual". ${ }^{16}$

La tarifa económica del cine que permitía la asistencia de un numeroso público, ${ }^{17}$ el amplio interés que despertaba en la población la llegada de este medio moderno y la ausencia de otros espacios más o menos constantes de entretenimiento en el país eran motivos para que los empresarios vieran en el cine mayores posibilidades de desarrollo comercial. ${ }^{18}$ Además, es posible que el amplio público asistente encontrara en el cine un medio que como ningún otro facilitaba la ampliación de la realidad. Por primera vez, la experiencia de contacto con el mundo exterior y sus novedades fueron posibles de manera más directa para los espectadores comunes y no solo para aquellos que podían viajar a otros países y leer la prensa.

15. "De Barranquilla, Colombia”, Cine Mundial (New York) marzo de 1923: 176.

16. Francisco Montero, "Trade with South America”, The Moving Picture World (New York) 27 de febrero de 1915: 1269.

17. A diferencia del teatro, el cine tuvo un carácter democrático al no contar con mayores restricciones en cuanto a su acceso y al ser barato: sus precios de admisión durante los años 1910 y 1920 oscilaban entre 10, 20 y 35 centavos - llegaron a un límite máximo de 60 centavos para palcos en 1928, y solo con respecto a las mejores producciones-. Aquello era un gasto factible, por ejemplo, para un jornalero en Bogotá, que en 1915 recibía un salario diario entre 60 centavos y $\$ 1$ por día. Si comparamos los precios del cine con los del teatro, notamos que la silla más económica para ver una presentación dramática, por ejemplo, en el Teatro Municipal de Cartagena costaba dos veces más que la acomodación de "galería" de una función de cine que costaba 10 centavos, la acomodación más barata oscilaba entre 30 centavos a \$1. "Carta del cónsul de Barranquilla a A. J. Roser", Barranquilla, 11 de junio de 1915. NARA, College Park, RG 84, Barranquilla, Colombia Consular Post, vol. 122, s.f.; Harold B. Meyerheim, cónsul general de los Estados Unidos en Medellín, "Informe de cinematografía en Medellín, Colombia”, Medellín, 16 de agosto de 1915. NARA, College Park, RG 84, Colombia Consular Post, RG 84, vol. 122, s.f.

18. En la época del cine silente, los cines de los principales centros urbanos ofrecían funciones en la vespertina y en la noche durante 3 o 4 días a la semana, incluido los domingos. Harold B. Meyerheim, cónsul general de los Estados Unidos en Medellín, "Informe de cinematografía en Medellín, Colombia”, Medellín, 16 de agosto de 1915. NARA, College Park, RG 84, Barranquilla, Colombia Consular Post, vol. 122, s.f. 


\section{El reciclaje de películas}

En 1910 el interés de Estados Unidos por conquistar los mercados cinematográficos y competir con industrias filmicas europeas como la italiana, francesa, alemana y danesa, que a mediados de esta década sobresalían en materia de producción, se extendió a Latinoamérica y a numerosas partes del mundo. Pese a que durante la Primera Guerra Mundial creció el número de películas hechas en Italia, las dificultades económicas de sus estudios para abastecerse de equipamiento filmico socavaron su potencial para competir con los norteamericanos y, aunque tuvo un leve resurgimiento después de 1919, desde 1920 declinó la cantidad de producciones. ${ }^{19}$ Di Doménico y Belisario Díaz, quienes compraban durante la Primera Guerra las producciones francesas e italianas, y en menor medida norteamericanas, vieron su negocio afectado por la falta de abastecimiento de películas europeas, por lo que debieron suspender las funciones de cine temporalmente, combinarlas con otros espectáculos u optar por repetir los filmes.

Esta situación hizo del cine un entretenimiento endeble y dependiente de otras entretenciones, lo que despertaba quejas en los espectadores, así como llamados de atención a los empresarios de cine por parte de las autoridades de inspección municipal. Además, la escasa población flotante en las ciudades hacía necesario que los programas fueran cambiados constantemente, y solamente la película más exitosa pudiese ser repetida 3 o 4 veces. ${ }^{20}$

Hacia mediados de la década de 1910 las películas norteamericanas llegaban a Colombia con cierto retraso, lo que desató las quejas de algunos espectadores no solo por tener que ver viejos estrenos, sino también por la distancia entre las últimas noticias de Hollywood — que circulaban, por ejemplo, en magazines de cine internacionales como Cine Mundial - y lo que se proyectaba en los cines y se publicaba en las revistas locales. ${ }^{21}$ Es el caso de Luis Martínez, un corresponsal colombiano que en 1917 informaba sobre las últimas exhibiciones en Bogotá. Al notar la ausencia de "infinidad de cintas sorprendentes, en muchos episodios que aquí no conocemos", y para que Colombia se adelantara en materia cinematográfica, Martínez sugería que las casas cinematográficas de Nueva York se combinaran

19. Kristin Thompson, "The Rise and Fall of Film Europe", "Film Europe" and "Film America". Cinema, Commerce and Cultural Exchange, 1920-1939, eds. Andrew Higson y Richard Maltby (Exeter: University of Exeter Press, 1999) 58; Kristin Thompson, Exporting Entertainment. American in the World Film Market, 1907-1934 (Londres: BFI Publishing, 1985).

20. Harold B. Meyerheim, "Informe de cinematografia en Medellín, Colombia”, Medellín, 16 de agosto de 1915. NARA, College Park, RG 84, Barranquilla, Colombia Consular Post, vol. 122, s.f.

21. Así, en 1918, en Cine Mundial se lee: "entre las revistas cinematográficas que llegan a esta redacción, 'Películas' de Bogotá de los hermanos Di Doménico, se lleva la palma en atraso. Si los colombianos se conforman con el material anunciado en el periódico aludido, vemos en perspectiva una fortuna para el primer empresario que se deje caer por aquella república con algunas películas nuevas de las marcas que hoy van a la cabeza de la escena muda". "Baturrillo Neoyorquino", Cine Mundial (New York) octubre de 1918: 637. 
con las de Di Doménico y el Kine Universal y, de esta manera, hicieran del cine un entretenimiento variado y rentable en las principales ciudades de Colombia. ${ }^{22}$

Desde una perspectiva similar, en 1915, en un artículo de Motion Picture News se lee que una espectadora colombiana le dijo a un norteamericano que el público colombiano era tan crítico como el estadounidense. Según la espectadora, las películas de su país no tendrían éxito en Colombia si los empresarios fílmicos norteamericanos seguían enviando cintas de comedias, del oeste salvaje y de detectives de segunda mano, "aunque si esas últimas 'son buenas', el público no tiene problema", aclaraba. "Dejen de usar Colombia y el resto de América del Sur para una 'papelera' en la que deshacerse de las obras que el público estadounidense se niega a ver. Entonces habrá una oportunidad", puntualizaba. ${ }^{23}$

La percepción de que Kine Universal y Di Doménico Hermanos eran firmas que monopolizaban el mercado de la distribución de películas en Colombia era objeto de inconformidad en las revistas cinematográficas locales e internacionales. Cine Mundial en 1917 publicó una carta que habría enviado una espectadora de Medellín al director de la publicación en la cual se quejaba por el mal servicio que dos empresas cinematográficas daban al público. La lectora y espectadora pedía la cooperación de su editor para lograr que en Colombia se establecieran algunas productoras norteamericanas, "que nos libren de la especie de monopolio de las dos empresas de cine que nos traen aburridas, pues se han puesto de acuerdo para mejor exprimir el jugo de sus habitantes". En la carta agregaba que las empresas de los señores Di Doménico y Belisario Díaz usaban como pretexto la guerra para ofrecer a los espectadores constantes repeticiones. El público se ve obligado a pagar las entradas a cine — cuyas ganancias no se invierten en buenas y variadas películas - para ver producciones de Europa y Estados Unidos de segunda categoría, pues ante la falta de otros entretenimientos "no queda otro recurso que el cine, y esto por la mar de razones: siempre es mejor estar en el cine y gozar de la suave oscuridad de la proyección, que estar en casa, con mamá al lado, y alumbradas a “jiorno",".24

Sobre este punto, en 1919 un cónsul de Estados Unidos en Cartagena afirmaba que las películas norteamericanas en Colombia estaban perdiendo acogida, porque solo se importaban viejos estrenos. Varios agentes de los consulados de Estados Unidos coincidían en la idea según la cual, si se trataba de incrementar la popularidad de sus películas en Colombia, se debería tener en cuenta que aquellas "pasadas de moda no son más adecuadas para el público colombiano que lo que son para

22. Luis Martínez Casado, "Lírico", Cine Mundial (New York) noviembre de 1917: 572.

23. "South America offers fruitful field for films of real merit", Motion Picture News 12 (New York) 6 de noviembre de 1915: 61.

24. “¿Será verdad?”, Cine Mundial (New York) diciembre de 1917: 610. 
el público norteamericano";25 el hecho de que las películas de estudios conocidos fueran la minoría era una queja constante en la década de $1910 .{ }^{26}$

Parece ser que una razón por la cual las dos únicas agencias de cine reciclaban las películas se debía a los altos precios de las cintas norteamericanas. Así, en 1917 un cónsul norteamericano declaró que los dueños de estas empresas "son sumamente parciales a la compra de películas francesas e italianas y no son inclinadas a favorecer las norteamericanas. Argumentan que ellas no pueden compararse en cualidades artísticas con las europeas". ${ }^{27}$

Ante la imposibilidad de invertir dinero en estrenos estadounidenses, Di Doménico decía a las audiencias de Películas, su revista de cine, que los filmes europeos tenían mejores cualidades estéticas y de producción que los estadounidenses. Los agentes consulares norteamericanos contradecían las afirmaciones de Di Doménico cuando expresaban al Departamento de Estado que la preferencia de las películas europeas por parte de aquellos empresarios se debía, sobre todo, a que eran más accesibles económicamente y no porque fueran "consideradas más artísticas", por lo que se le negaba al público colombiano la oportunidad de ver lo que los diplomáticos consideraban "las mejores producciones americanas". ${ }^{28}$

\section{Ampliando el repertorio de películas hollywoodenses}

Los seriales cinematográficos de crímenes y aventuras, en los que se ahondará más adelante, hacían parte del repertorio fílmico de segunda mano que compraban las empresas locales, pero que, a diferencia de otras películas usadas, cautivaron al público colombiano y otorgaron por primera vez prestigio a las producciones hechas en Estados Unidos, que al principio no eran populares. De acuerdo con información consular, producciones como El misterio del millón de dólares (serie de 23 episodios, realizada por Thanhouser Film en 1914), La máscara de los dientes blancos y Los misterios de Nueva York (realizadas por Pathé Exchange en 1914 y 1915 , respectivamente), esta última dirigida por el francés Louis Gasnier y protagonizada por la heroína norteamericana Pearl White o Perla Blanca — como se le llamó en

25. "Opportunities for America Motion Picture Films in the Consular District of Cartagena", Cartagena, 3 de julio de 1919. NARA, College Park, RG 84, Cartagena, Colombia Consular Post, vol. 154, s.f.

26. Claude E. Guyant, "Report: Market for Motion Picture Films", Barranquilla, 7 de agosto de 1917. NARA, College Park, RG 84, Barranquilla, Colombia Consular Post, vol. 122, s.f.

27. Claude E. Guyant, "Report: Market for Motion Picture Films", Barranquilla, 7 de agosto de 1917. NARA, College Park, RG 84, Barranquilla, Colombia Consular Post, vol. 122, s.f.

28. Harold B. Meyerheim, “Informe de cinematografia en Medellín, Colombia”, Medellín, 16 de agosto de 1915. NARA, College Park, RG 84, Barranquilla, Colombia Consular Post, vol. 122, s.f.; Claude E. Guyant, "Report: Market for Motion Picture Films", Barranquilla, 7 de agosto de 1917. NARA, College Park, RG 84, Barranquilla, Colombia Consular Post, vol. 122, s.f. 
América Latina_- "son series que han tenido las casas de cine repletas y de manera indiscutible, han contado con una aprobación general". ${ }^{29}$

En 1917 un cónsul norteamericano en Barranquilla le contó a una firma cinematográfica estadounidense que tras el éxito de los seriales de folletín referenciados: "se espera que compradores estén más interesados en obtener películas americanas, especialmente si ellas pueden conseguirse a precios que compitan con los precios de las europeas". Por ello, el cónsul informaba que "hay una buena oportunidad para el negocio de películas americanas de tres o cuatro años antes que han sobrepasado su utilidad en Estados Unidos, pero que debería ser completamente nuevas en Colombia". ${ }^{30}$ Por su parte, en 1919, el cónsul norteamericano en Cartagena se dirigió al Departamento de Estado contándole que recientemente Di Doménico y Díaz "se han venido convenciendo por la experiencia actual de que el público exigente en materias de gustos está cansado de las películas italianas ordinariamente baratas que han sido exhibidas aquí en el pasado", y aseguraba que ellos estaban considerando conseguir películas al estilo de los seriales americanos de la rama norteamericana Pathé Exchange. ${ }^{31}$

Con el propósito de renovar las producciones seriales que habían sido pasadas varias veces en el circuito regular de exhibición a nivel nacional, los agentes de las dos empresas de cine emprendieron viajes a Estados Unidos en enero de 1920 para hacer negocios directamente con las casas hollywoodenses. ${ }^{32}$ Por una parte, Di Doménico Hermanos y sus representantes viajaron a Nueva York en 1920, se fotografiaron con la estrella serial Juanita Hansen y se entrevistaron con periodistas

29. Luis Martínez Casado, "Crónica de Colombia", Cine Mundial (New York) enero de 1918: 40; Claude E. Guyant, "Report: Market for Motion Picture Films", Barranquilla, 7 de agosto de 1917. NARA, College Park, RG 84, Barranquilla, Colombia Consular Post, vol. 122, s.f.; Claude E. Guyant, "Report: Market for Motion Picture Films", Barranquilla, 6 de noviembre de 1919. NARA, College Park, RG 84, Barranquilla, Colombia Consular Post, vol. 143, s.f.

30. "Carta del cónsul de Barranquilla a Oceanic Film Corporation", Barranquilla, 12 de julio de 1917. NARA, College Park, RG 84, Barranquilla, Colombia Consular Post, vol. 122, s.f.

31. "Opportunities for America Motion Picture Films in the Consular District of Cartagena", Cartagena, 3 de julio de 1919. NARA, College Park, RG 84, Cartagena, Colombia Consular Post, vol. 154, s.f.; Hoffman Philip, "Answer to Questionnaire on Motion Picture Market in Latin America", Bogotá, 4 de octubre de 1919. NARA, College Park, RG 84, Diplomatic Post Colombia, vol. 220, s.f.

32. Parece ser que para los Di Doménico Hermanos era más rentable comprar una serie de cine y exhibir dos o tres de sus episodios (de aproximadamente unos 23) de manera consecutiva en cada función nocturna, que comprar largometrajes cuya duración se agotaba en una sola noche, lo que implicaba la compra inmediata de nuevo material filmico. De acuerdo con un informe consular, "con solo exhibir 6 u 8 seriales norteamericanos al año, los Di Doménico garantizaban tener sus casas de cine repletas". Claude E. Guyant, "Report: Market for Motion Picture Films", Barranquilla, 7 de agosto de 1917. NARA, College Park, RG 84, Barranquilla, Colombia Consular Post, vol. 122, s.f.; Claude E. Guyant, "Report: Market for Motion Picture Films", Barranquilla, 6 de noviembre de 1919. NARA, College Park, RG 84, Barranquilla, Colombia Consular Post, vol. 143, s.f.; Hoffman Philip, "Answer to Questionnaire on Motion Picture Market in Latin America”, Bogotá, 4 de octubre de 1919. NARA, College Park, RG 84, Diplomatic Post Colombia, vol. 220, s.f. 
norteamericanos. Allí Francisco declaró que el público era cada vez más exigente y que quería ver los mejores dramas y comedias, como aquellos de la estrella cómica Harold Lloyd y, particularmente, las producciones en serie de aventuras y acción, al estilo Million Dollars Mistery, como: Las huellas misteriosas y La ciudad perdida, de la casa Selig, y El peligro oculto, de la casa Arrow, entre otros. ${ }^{33}$

Por su parte, de manera similar a la firma Di Doménico Hermanos, Belisario Díaz en los años veinte no dejó de comprar largometrajes y seriales europeos, particularmente franceses de la casa Parisien y Pathé Consortium. En mayo de 1923, este empresario viajó a Nueva York donde se entrevistó con Nita Naldi, estrella de Paramount, firmó contratos cinematográficos con las casas productoras Paramount, Universal y Select, y adquirió las "mejores producciones americanas" de los últimos cinco años, en las cuales aparecían reconocidas artistas silentes de las pantallas de Broadway como Gloria Swanson, Pola Negri y las hermanas Talmadge. ${ }^{34}$

\section{El "buen” y "mal gusto" cinematográfico}

Las definiciones de "buen gusto" y "mal gusto" no son manifestaciones instintivas o juicios espontáneos, sino que responden a las relaciones que los individuos y grupos sociales establecen con una actividad u objeto de comunicación cultural - la música, la pintura, el cine, la literatura - y al contexto en que esas relaciones se forman y desarrollan. Como lo formula Pierre Bourdieu: "la historia del gusto, individual o colectivo, basta para desmentir la ilusión de que objetos tan complejos como las obras de arte, producidas según leyes de construcción elaboradas a lo largo de una historia relativamente autónoma, sean capaces de suscitar, únicamente por sus propiedades formales, preferencias naturales". ${ }^{35}$ Desde esta perspectiva, el gusto no es natural, sino que acontece en una sociedad determinada y en un momento dado del tiempo y depende, ante todo, del "dominio práctico, adquirido por la frecuentación de un objeto cultural determinado o por un aprendizaje explícito de un código propiamente artístico". ${ }^{36}$ Es decir, deriva de la capacidad de un individuo o grupo para conferir un significado a un producto cultural dentro del horizonte de expectativas de su campo de formación artística.

Esta perspectiva sociológica problematiza la naturalidad de los gustos y los juicios artísticos al dar cuenta de su carácter íntimo, pero también social y cambiante. Asimismo, contribuye a la idea de que las formaciones de los gustos deben estudiarse de manera que no se separen los ámbitos de la producción y del consumo; es decir, aquello que la industria cultural ofrece (la publicidad, las películas y otros objetos de difusión) y las maneras en que el público responde, aprecia y

33. Exhibitors Herald (Chicago) abril-junio de 1920: 60.

34. Cine Mundial (New York) agosto de 1923: 498.

35. Pierre Bourdieu, El sentido social del gusto (Buenos Aires: Siglo XXI, 2010) 67.

36. Bourdieu 73. 
resignifica. En este sentido, la apropiación simbólica de una actividad cultural o medio de comunicación mediante el gusto podría estudiarse desde el cruce entre las circunstancias concretas de su producción, la intención del productor y el grado en el cual el público incorpora los significados propuestos por la obra artística u objeto cultural. ${ }^{37}$

Involucrar a los consumidores en la formación del gusto nos lleva a indagar acerca de las maneras en que incorporan los significados propuestos por el objeto cultural disfrutado. Por ejemplo, si en el momento de apreciación ellos responden a convenciones o códigos impuestos por el campo de formación de la obra o si, por el contrario, ellos ejercen su "libertad interpretativa" sin cuestionar si la manera en la que están entendiendo el objeto es acertada o pertinente. ${ }^{38}$ Se podría decir que los consumidores de cine de la época de estudio participan más bajo esta última forma de apropiación, en cuanto ellos disfrutan de las películas con un grado mayor de libertad y desentendimiento en comparación con aquellas artes que forman parte de "la producción restringida" y que se dirigen a públicos cultivados, y que a inicios del siglo XX ya contaban con una tradición artística como es el caso de la pintura, el teatro y la ópera.

Pero, además, esa forma de "apreciación desentendida" que ejercen los espectadores se relaciona con la técnica de reproducción masiva y los altos costos de producción — para hablar en términos de Walter Benjamin_, ${ }^{39}$ los cuales inciden en el hecho de que la industria cinematográfica integrara a los públicos más heterogéneos con el propósito de generar ganancias económicas. Esta inclusión se hizo sin que interesara su bagaje cultural, sino más bien sus expectativas y gustos, lo que en una época de formación del cine no era tan previsible, pues las productoras extranjeras y los empresarios filmicos en las décadas de 1910 y 1920 tuvieron que conocer el tipo de películas que gustaban y las que no (lo que significaba probar y fallar), hasta que ya en los años treinta se lograra un mercado filmico con géneros definidos — acción y aventura, cómico, dramático, terror - para una enorme masa de consumidores y gustos más o menos estandarizados.

En ese sentido, la reproductibilidad masiva del cine -inherente a su técnica- no garantizaba por sí sola la popularidad del espectáculo. Para que un tipo de cine se convirtiera en popular había que recurrir a un conjunto de estrategias y temáticas capaces de capturar la atención y las expectativas de los espectadores sin que, en el intento, se llegara a perturbar sus sensibilidades y gustos. A finales de la década de 1910 y en los años 1920, agentes de las comercializadoras filmicas norteamericanas con el apoyo del Departamento de Estado preguntaban a los

37. Bourdieu 75 .

38. La obra de Umberto Eco, en gran parte, se ha dedicado a estudiar cómo el consumo de un texto pasa por grados distintos de "interpretación", en cuanto el lenguaje escrito o visual despliega infinitas remisiones a las que el lector o el espectador puede seguirles la pista en busca de uno o varios significados, que incluso pueden alejarse de la intención del texto o la obra. Umberto Eco, Interpretación y sobreinterpretación (Cambridge: Cambridge University Press, 1990) 51.

39. Walter Benjamin, La obra de arte en la época de su reproductibilidad técnica (México: Ítaca, 2003) 61. 
cónsules norteamericanos en Colombia y, en general, en América Latina qué contenidos fílmicos eran deseables — o no- para el público; en 1917, por ejemplo, el cónsul de Barranquilla aseguraba que "el realismo" no era deseado por el público. ${ }^{40}$

Para ilustrar esto, en un reporte consular consignó que una compañía local había mostrado la película The Poiseeners of Chicago (realizada en 1914 por All-Star Feature Corporation), basada en la novela de Upton Sinclair titulada The Jungle, y, aunque el filme "estuvo bien anunciado y el cine estuvo repleto, todas las características desagradables hicieron su aparición. El resultado no fue favorecedor ya sea para los americanos o las películas americanas", ${ }^{41}$ anotaba el cónsul. De este modo, mostraba el grado de desatino de The Poiseeners of Chicago, que con cierto estilo documental daba a conocer el desaseo y la pobreza en las carnicerías de Chicago y, por lo tanto, sobrepasaba la medida justa del "realismo". ${ }^{4}$

Las fuentes consulares también sugieren que los espectadores colombianos no apreciaban las cintas con contenido "patriótico". ${ }^{43}$ Este disgusto entre las audiencias lo provocaba, por ejemplo, las vistas de la bandera estadounidense, por lo que los exhibidores de la compañía Di Doménico optaban por no exhibir las películas que presentaran tramas patrióticas. Por su parte, los trabajadores de Belisario Díaz tomaron la iniciativa de recortar el celuloide y "eliminar la bandera norteamericana en las vistas exhibidas por la fuerte opinión pública actual", como señalaba el cónsul citando a Díaz. ${ }^{44}$

En las décadas de 1910 y 1920, los géneros y los gustos cinematográficos aún no estaban uniformados y, en gran parte, esa formación de gustos se dio en el marco de la competencia — y otras veces de la colaboración — entre la industria filmica europea y la norteamericana; esta última tomó contenidos fílmicos europeos, como las producciones en serie, para reinventarlos y publicitarlos al estilo

40. Claude E. Guyant, "Report: Market for Motion Picture Films", Barranquilla, 7 de agosto de 1917. NARA, College Park, RG 84, Barranquilla, Colombia Consular Post, vol. 122, s.f.; Hoffman Philip, "Answer to Questionnaire on Motion Picture Market in Latin America", Bogotá, 4 de octubre de 1919. NARA, College Park, RG 84, Diplomatic Post Colombia, vol. 220, s.f. Una opinión similar sobre el gusto del público del cine colombiano en M. Balley, "Películas en Latinoamérica", West Coast Leader (Lima) 10 de julio de 1920: 8-10.

41. Claude E. Guyant, "Report: Market for Motion Picture Films", Barranquilla, 7 de agosto de 1917. NARA, College Park, RG 84, Barranquilla, Colombia Consular Post, vol. 122, s.f.; Hoffman Philip, "Answer to Questionnaire on Motion Picture Market in Latin America", Bogotá, 4 de octubre de 1919. NARA, College Park, RG 84, Diplomatic Post Colombia, vol. 220 , s.f.

42. Se trata de una historia "cuyo personaje principal es un inmigrante lituano contratado por una planta de empaques de Chicago. Aplastado por las condiciones de trabajo, la violencia policial y la falta de escrúpulos de un capataz, el hombre encuentra cierta medida de esperanza cuando vaga en una reunión socialista y es atravesado por un orador inspirado en Eugene V. Debs". Richard Abel, Encyclopedia Early Cinema (Londres / New York: Routledge, 2005) 530-531.

43. Hoffman Philip, “Answer to Questionnaire on Motion Picture Market in Latin America”, Bogotá, 4 de octubre de 1919. NARA, College Park, RG 84, Diplomatic Post Colombia, vol. 220, s.f.

44. Hoffman Philip, "Answer to Questionnaire on Motion Picture Market in Latin America", Bogotá, 4 de octubre de 1919. NARA, College Park, RG 84, Diplomatic Post Colombia, vol. 220, s.f. 
norteamericano. Entre 1918 y 1919 se exhibió en las salas de Colombia la serie episódica Judex (realizada en 1914 por Gaumont). Judex (personaje creado por los franceses L. Feuillade y A. Bernede) a diferencia de Fantômas no era "un amo del miedo", sino un justiciero que se proponía vengar la muerte de su padre en nombre del bien. ${ }^{45}$ El éxito obtenido por esta serie lo había antecedido Nick Carter (realizada en 1908 por Eclair), primer filme policíaco de episodios grabado en Francia porVictorin Jasset quien, según George Sadoul, a pesar de tomar héroes de los folletines populares norteamericanos, escribía historias improvisadas y las situaba en los suburbios de París. ${ }^{46}$ De acuerdo con el cónsul norteamericano en Barranquilla, en 1915 Nick Carter "llena el nicho para los cuentos de detectives, y sus películas son lo suficientemente divertidas para atraer al público colombiano". ${ }^{47}$

El éxito comercial que tuvo Francia con la adaptación cinematográfica de folletines populares fue imitado e intensificado por la industria cinematográfica norteamericana, la cual desde 1913, empezó a contratar directores europeos y a producir seriales masivos con estrellas norteamericanas con el propósito de ampliar su público de cine. Es probable que recurriera a adaptar grandes novelones y best sellers de folletín — que antes del cine habían contribuido a la democratización de la cultura- ${ }^{48}$ en parte porque en la década de 1910 la narración cinematográfica aún no se independizaba de entretenimientos de mayor data, como el teatro y la literatura. Lo que hacía que directores y guionistas de cine no contaran con suficientes recursos imaginativos para inventar un lenguaje y estilo cinematográfico capaz de contar historias, que reuniera los gustos de un público cada vez más numeroso y diverso. Se sabe, por ejemplo, que en el cine de los primeros tiempos las productoras filmicas, sobre todo europeas, recurrieron a adaptar el repertorio de lo ya conocido, es el caso de aquellas novelas históricas de mediados del siglo XIX: Los miserables, La dama de las camelias y El conde de Montecristo, y a revivir los misterios religiosos en cintas como Cristhus y La pasión. ${ }^{49}$

El movimiento, el suspenso, el final feliz, las situaciones peligrosas que ocurren a los héroes con quienes se identifican los espectadores y en los que la reflexión se excluye para dar paso a la acción, la velocidad y la destreza física son elementos que remiten a la industria norteamericana de hoy. No obstante, ya empezaban a evidenciarse en las producciones que circulaban a nivel mundial en las primeras décadas del siglo XX. En el caso particular de Colombia fueron las comedias y,

45. Concha 163 .

46. Georges Sadoul, "El arte mudo (1895-1930)", Historia del cine mundial, ed. Georges Sadoul (México: Siglo XXI, 1972) 53.

47. Isaac A. Manning, "Cinematograph Films for Colombia”, Barranquilla, 25 de mayo de 1915. NARA, College Park, R G 84, Barranquilla, Colombia Consular Post, vol. 122.

48. Umberto Eco, El superhombre de masas (Bogotá: Debolsillo, 2012).

49. Sobre "el cine de los primeros tiempos" y los diferentes "momentos" técnicos y estilísticos del cine silente, véase Tom Gunning, "The Cinema of Attraction(s): Early Film, Its Spectator and the Avant-Garde", Early Cinema. Space, Frame, Narrative, ed.Thomas Elsaesser (Londres: British Film Institute, 1990) 56-62. 
sobre todo, las series de crímenes y aventuras norteamericanos las que tuvieron gran acogida en el público, al punto de desplazar paulatinamente los gustos cinematográficos de Europa hacia Estados Unidos.

Pero ¿en qué se diferenciaban las películas europeas de las películas norteamericanas? ¿por qué las primeras iban ganando gradualmente en 1920 más adeptos que las segundas? A juzgar por las revistas de cine y los informes consulares, las cintas con contenido dramático eran generalmente italianas y francesas. Se trataba de historias con "abundante interés amoroso y aventuras", pero, como aclara en 1917 el cónsul norteamericano de Barranquilla al Departamento de Estado de Estados Unidos, "no se trata de las aventuras de las películas seriales americanas donde el héroe continuamente se enfrenta a una banda de criminales, sino de dramas de época; comedias y tragedias [...] en las que damas con rígidas y finas ropas, y apuestos caballeros, siempre encuentran la aprobación del público" ${ }^{50}$ Desde una perspectiva similar, en 1919 el cónsul de Barranquilla informaba que las casas de exhibición locales casi siempre proyectaban historias de aventura americanas, mientras que la mayoría de películas italianas eran historias de drama y amor. ${ }^{51}$

\section{El gusto cinematográfico condicionado por la oferta cinematográfica}

Como se mencionó, el hecho de que las dos empresas filmicas en Colombia no compraran los últimos estrenos norteamericanos se debió menos a las voluntades de sus empresarios y más a sus dificultades de comerciar largometrajes dramáticos estadounidenses, entre otras cosas, por sus altos costos de transporte e importación. En este sentido, es preciso tener en cuenta que los gustos cinematográficos de los colombianos se formaron a partir de un repertorio muy limitado de producciones europeas y norteamericanas que circularon en las décadas de 1910 y 1920 y en el cual puede rastrearse, a grandes rasgos, dos tipos de oferta cinematográfica: por un lado, se encontraban aquellas cintas "de época y sentimentales", usualmente europeas, y, por el otro, las películas en serie "sensacionales" norteamericanas.

A las primeras pertenecen las películas nombradas "de arte" por la crítica cinematográfica de aquel momento, ${ }^{52}$ generalmente dramas franceses como Los miserables (realizada por Pathé Frères en 1913) y La novela del grumete (realizada por

50. Claude E. Guyant, "Report: Market for Motion Picture Films", Barranquilla, 7 de agosto de 1917. NARA, College Park, RG 84, Barranquilla, Colombia Consular Post, vol. 122, s.f.

51. Claude E. Guyant, "Report: Market for Motion Picture Films", Barranquilla, 6 de noviembre de 1919. NARA, College Park, RG 84, Barranquilla, Colombia Consular Post, vol. 143, s.f.

52. Hay que recordar que el cine de los primeros tiempos recurrió al teatro y a la literatura "legítima" para atraer a las clases altas y elevar el estatus cultural del primer cine narrativo. Este movimiento se llamó en 1908 Film d'art cuya adaptación teatral al cine de El asesinato del duque de Guisa (realizada por Le Bargy y Pathé Frères en 1908) constituyó el primer y último éxito de esta iniciativa que se vio desplazada por el creciente interés de los espectadores hacia el cine narrativo norteamericano y la adaptación cinematográfica de novelas populares. Sadoul 87-88. 
Gaumont), que "han emocionado al público y se han repetido mucho". ${ }^{53}$ Por el estilo también se destacaron las películas italianas, como ¿Quo Vadis? (realizada por Cines en 1912), Los misterios de París (Pathé Frères,1912) y la famosa cinta Cabiria (1914), cuyo principal personaje era Maciste, interpretado por el gigante y fuerte Bartolomeo Pagano. ${ }^{54}$ Cabiria, según George Sadoul, se destacaba por sus enormes escenografias y por atractivos como las batallas, los incendios de grandes edificaciones y el sacrificio de niños. ${ }^{55}$

Por otro lado, estaban las series de aventura norteamericana de largometraje que se pasaban varias noches por episodios hasta llegar al desenlace final. Estas cintas fueron producidas entre 1912 y 1915 por las firmas norteamericanas Universal, Thanhouser y, especialmente, Pathé Exchange, rama norteamericana de French Pathé que en 1921 se separó de su empresa matriz francesa; en Colombia y otras partes de América Latina estas series fueron comercializadas a partir de $1916 .{ }^{56}$ Entre las primeras cintas por episodios exhibidas en el país se destacan El misterio del millón de dólares (realizada porThanhouser en 1914) y Los misterios de Nueva York (realizada por Pathé Exchange entre 1914 y 1915). ${ }^{57}$ De esta manera, a finales de la década de 1910, las películas “de arte", en su mayoría dramas italianos y franceses - y en menor medida daneses_-, convivían en los recintos de cine con las cintas de episodios norteamericanas. ${ }^{58}$

Un informe consular de 1919, relativo a las diferencias entre los gustos cinematográficos, señalaba que una parte del público "prefiere películas refinadas y la otra gusta de lo sensacional" o de "situaciones asombrosas de crimen y asesinato", y este último grupo es el que asiste al cine Olympia más que a otro cine en Bogotá, y es allí donde se presentaba la audiencia más numerosa. ${ }^{59}$ Hay que advertir que la división de gustos cinematográficos no necesariamente conduce a una distinción social y de clase. Sobre este punto, por ejemplo, Películas, señaló en 1919 que "la serie americana seduce al burgués y al obrero, lo mismo que al intelectual y al

53. Luis Martínez Casado, "Lírico", Cine Mundial (New York) noviembre de 1917: 572.

54. “Crónica Maciste”, Películas (Bogotá) 7 de octubre de 1916.

55. Según Sadoul, la libertad cinematográfica para transportar al espectador a través del tiempo y el espacio y la construcción de enormes escenógrafas de cintas italianas como Quo Vadis y Cabiria influenciarían años más tarde a Hollywood en la producción de cintas como Intolerancia (1916) y Ben Hur (1925). Sadoul 87-88.

56. Entre 1911 y 1914, Estados Unidos produjo seriales filmados para su consumo interno; desde 1915 hasta comienzos de 1920, cuando la producción serial había sido lo suficientemente explotada por las compañías norteamericanas, el mercado de distribución se volcó hacia el extranjero.Véase Rudmer Canjels, Distributing Silent Film Serials. Local Practices, Changing Forms. Cultural Transformation (New York / Londres: Routledge, 2011) 44-46.

57. Luis Martínez Casado, "Crónica de Colombia”, Cine Mundial (New York) enero de 1918: 40.

58. Luis Martínez Casado, "Lírico", Cine Mundial (New York) noviembre de 1917: 572.

59. Hoffman Philip, "Answer to Questionnaire on Motion Picture Market in Latin America", Bogotá, 4 de octubre de 1919. NARA, College Park, RG 84, Diplomatic Post Colombia, vol. 220, s.f. 
artista: he aquí el secreto del éxito de cintas de folletín como: La huella del tigre, La casa del odio y Manos arriba". ${ }^{60}$

Parece ser así que las series de cine norteamericanas, a diferencia de las cintas italianas, se caracterizaban por su alta dosis de irrealidad y por las hazañas inverosímiles y peligrosas de sus héroes y heroínas, que para algunos espectadores despertaban asombro y admiración. ${ }^{61}$ En 1921, un corresponsal colombiano señalaba que los públicos que no comprendían "el truco cinematográfico”, no concebían "cómo es posible que una mujer, como todas las mujeres, sea capaz de tales hazañas, de tales audacias casi siempre inverosímiles. No conciben a Juanita Hansen en frente de un tigre o de un leopardo, ni a Ruth Roland sobre la hoguera, casi asfixiándose". ${ }^{62}$

Esta impresión es interesante para acercarnos a las relaciones del público de la época con el mundo imaginativo y la idea de lo posible cinematográfico que se ofrecía las proyecciones de cine. Al respecto, el escritor antioqueño Luis Tejada en 1922 escribió en contra de los detractores de las cintas de aventuras norteamericanas, pues consideraba que estas conquistaban los públicos de Europa y América, incluidas las clases medias y personas cultas, y porque, a diferencia de las novelas realistas, el cine presentaba "lo absurdo posible, lo inverosímil real [...] bajo las formas más sencillas, fuertes y exaltantes”. En su opinión: "La afición a las películas de aventureras $[. .$.$] es una reacción inconsciente pero decisiva contra el realismo$ árido y analítico que se había impuesto en la novela y en el teatro [...] los héroes soberanos de Zola y sus discípulos los aburrían [...] y las sutiles elucubraciones psicológicas". Tejada agregaba datos sobre la expansión de la idea de "lo posible en el cine" y las sensibilidades que despertaba la película de folletín al anotar que:

Lo cierto es que en las películas de aventuras americanas existe un profundo fermento de emoción, un nervio vital que conmueve al espectador porque va a tocar vivamente esas fibras heroicas [...] todos sufrimos cuando el león está a punto de comerse a la protagonista, o quisiéramos ser el enigmático y valeroso enmascarado que defiende a la pobre muchacha rubia contra los bandidos... Total... los hombres son todos, en el fondo, aventureros [...] la vida es una aventura perfectamente cinematográfica, con la diferencia de que, al final, siempre se lo come a uno el tigre. ${ }^{63}$

60. "Cuatro meses de temporada en el Olympia, los estrenos", Películas (Bogotá) abril de 1920: 20.

61. Para el teórico de cine Christian Metz lo "verosímil" o posible fílmico es aquello que no está lejos de lo deseable ni de lo conveniente. Así, el espectador puede creer en todas las desventuras grotescas por las que atraviesa un personaje cómico a causa de su avaricia, mala suerte o afectación, solo si ello se acomoda a las leyes de un género cinematográfico establecido como el cómico. Christian Metz, Ensayos sobre la significación en el cine (1964 -1968), vol. 1 (Barcelona: Paidós, 2002) 251-265.

62. "Crónica de Colombia", Cine Mundial (New York) enero de 1918: 354.

63. Luis Tejada, Gotas de Tinta (Bogotá:Andes, 1977) 92-94. 


\section{La popularidad de las películas norteamericanas}

El serial norteamericano tenía sus adeptos y, a la vez, sus detractores. Es, por ejemplo, el caso de algunos cónsules norteamericanos que se quejaban porque los exhibidores en Colombia proyectaban por largas noches aventuras con cowboys y ofrecían al público "una pobre variedad". ${ }^{64}$ Ante los ojos de Claude E. Guyant, cónsul estadounidense de Barranquilla, "desde el vulgar slapstick y los baratos westerns a los seriales norteamericanos no ha habido un solo filme dramático americano de primera categoría mostrado en Colombia", aunque "hay cintas francesas e italianas que se exhiben en los entreactos y que algunas veces han sido muy buenas". ${ }^{65} \mathrm{~A}$ diferencia del público mayoritario, parece ser que a los cónsules norteamericanos no apreciaban los westerns por su baja calidad y tampoco los seriales de aventuras, porque ya habían caído en desprestigio en su país y sus escenas de robos y persecuciones "se prestaban para erróneas impresiones relacionadas con la vida de Estados Unidos" "66 como manifestaba en 1922 el cónsul de Cartagena. También en 1925 había un grupo de ciudadanos que exigían a la Alcaldía de Cundinamarca la estricta censura de "las películas llamadas de serie", que en su mayoría son "constituidas por escenas de asalto, de asesinato, de robo y de violencia, y siempre quedan burladas la autoridad y la policía, y ridiculizadas [...] cuando por escaso, llegan a intervenir o a aparecer en escena". ${ }^{67}$

Aun así, el gradual ascenso del cine norteamericano, al menos en su forma serial, coexistía con el descenso de los largometrajes europeos en el mercado de distribución local..$^{68}$ Así, por ejemplo, en 1917, después de la exhibición de los primeros episodios de los Misterios de Nueva York, en la Costa Atlántica el cónsul de la ciudad de Barranquilla escribió que "los espectadores están cansados de las marcas baratas y de las películas italianas y francesas anteriormente exhibidas". ${ }^{69}$ De manera similar, en Cine Mundial se lee que las cintas italianas que exhiben los Di Doménico ya no son del agrado del público, que ya no se considera satisfecho con los temas si no son del calibre de ¿Quo Vadis? o Cabiria. "Creo que la película

64. "Carta del cónsul norteamericano de Cartagena a Mr Don Hancock, Fox News", Cartagena, 5 de septiembre de 1922. NARA, College Park, RG 84, Cartagena, Colombia Consular Post, vol. 172, s.f.

65. Claude E. Guyant, "Report: Market for Motion Picture Films", Barranquilla, 7 de agosto de 1917. NARA, College Park, RG 84, Barranquilla, Colombia Consular Post, vol. 122, s.f.

66. "Carta del cónsul norteamericano de Cartagena a Zelznick Corporation, Producers and Distributors of Motion Pictures", Cartagena, 2 de mayo de 1922. NARA, College Park, RG 84, Cartagena, Colombia Consular Post, vol. 172, s.f.

67. Lester L. Schenare, "Censura de películas y espectáculos públicos en el distrito consular de Cartagena”, Barranquilla, 5 de diciembre de 1925. NARA, College Park, RG 59, Bogotá, General Records of Department of State, s.f.

68. "Carta del cónsul norteamericano en Barranquilla a The Selsnick Pictures Corporation", Barranquilla, 5 de abril de 1922. NARA, College Park, RG 84, Barranquilla, Colombia Consular Post, vol. 161, s.f.

69. "Carta del cónsul de Barranquilla a Oceanic Film Corporation", Barranquilla, 12 de julio de 1917. NARA, College Park, RG 84, Barranquilla, Colombia Consular Post, vol. 122, s.f. 
norteamericana folletinesca será la que mejor acogida tenga en lo futuro, debido a su carácter sensacional. Esto lo digo por el éxito de 'El misterio de millón de dólares", 70

En 1920, la revista Películas señaló que "las cintas francesas e italianas gozan de acogida, aunque no tanto como las series americanas". ${ }^{71}$ Por su parte, Cine Mundial informaba que con la exhibición de la serie episódica Ciudad perdida (realizada por Selig en 1920) con Juanita Hansen y Jorge Chesebro, conocido en Colombia como "Temerario", "fue tal la afluencia de gente, que hubo necesidad de repetir cada episodio tres veces", y en las noches de su estreno el cine Olimpia de los Di Doménico — que tenía una capacidad para 4,000 personas — "fue incapaz de contener toda la gente que deseaba ver al gran Temerario - el tipo de cowboy arriesgado y audaz- cuando al mismo tiempo se daba la misma cinta en los teatros Caldas y Cinerama, con llenos desbordantes", ${ }^{72}$

A mediados de la década de 1920 el cine serial empezó a perder su atractivo, creemos que esto se debe, por un lado, al hecho de que Belisario Díaz y la recién creada firma colombiana Cine Colombia iniciaron la importación de largometrajes de las casas Universal y Paramount. ${ }^{73}$ Las películas silentes de Cecil B. De Mille y el alemán Ernst Lubitsch despertaron gran interés en los espectadores, ya que presentaban a estrellas del momento como Gloria Swanson o Maurice Chevalier y se alejaban de los lugares comunes de los seriales de aventuras. ${ }^{74}$ Por otro lado, creemos que esa caída se debe a que en 1925 las películas en serie se fabricaban en menor cantidad en Estados Unidos, pues la industria norteamericana estaba ampliando los "géneros" cinematográficos y el serial cada vez más perdía interés y era menos rentable, inclusive en los mercados extranjeros. ${ }^{75}$

\section{Conclusiones}

Las maneras como estos empresarios de cine en Colombia direccionaron la actividad cinematográfica no solo pueden entenderse en razón a sus preferencias

70. "De Colombia”, Cine Mundial (New York) febrero de 1917: 87.

71. Películas 136 (Bogotá) julio de 1920.

72. "Crónica de Colombia”, Cine Mundial (New York) mayo de 1921: 354.

73. En 1927, un año antes de la llegada de la tecnología sonora —impulsada desde los Estados Unidos-, el Kine Universal de Belisario Díaz y los Di Doménico Hermanos se disuelven y venden la mayoría de sus acciones a Cine Colombia. Es probable que estos empresarios hayan decidido salir del negocio al no contar con una infraestructura cinematográfica adecuada para recibir esta nueva tecnología o con el capital suficiente para comprarla.

74. Así, al iniciar la era del cine sonoro, Mensajero Paramount citaba un anuncio del diario bogotano El Tiempo que promocionaba el musical El desfile del amor (realizado por Paramount en 1929) de Lubitsch, en el que se aseguraba que era la mejor cinta que se había exhibido en Bogotá en 1930. "La Paramount por el mundo", Mensajero Paramount (New York) febrero de 1931: 25.

75. "Las series de cine vuelven por sus laureles", Cine Mundial (New York) marzo de 1922: 149. Sobre el agotamiento de la producción serial filmada e impresa en Estados Unidos y su impulso en los mercados filmicos de Europa, véase Canjels 44-46. 
personales y su gran admiración por la cultura europea, de la cual hacían parte los Di Doménico, sino también por su deseo de estabilizar el entretenimiento del cine en el país. Para llevar adelante esta empresa debían enfrentar múltiples factores como la poca demanda de divertimentos culturales en una sociedad que recién empezaba a urbanizarse, las lógicas económicas propias del cine como negocio, las condiciones mundiales de la época y las contingencias de los gustos del público de las que, en últimas, dependía el éxito o no de las películas importadas.

Por su parte, empresarios hollywoodenses vieron como impedimentos para el éxito de la industria filmica estadounidense en Colombia las fuertes preferencias que mostraban los distribuidores locales por las películas europeas, así como sus limitaciones en cuanto a costos y preferencias filmicas de los públicos, condicionados, en parte, por la oferta disponible de películas a disposición de las dos empresas locales. No obstante, estas empresas no dejaron el progreso del cine a los vaivenes de la "oferta y la demanda", sino que se esforzaban por conocer los gustos del público local y negociar con este los contenidos filmicos y la calidad de los programas.

Además, aunque los espectadores ejercieran una "libertad interpretativa" con respecto a lo que veían en las pantallas, esa libertad se encontraba condicionada por la oferta de películas de la época y el poder de persuasión de la industria cultural cinematográfica. De ahí que espectadores no aceptaran espontáneamente las películas ni escogieran siempre en ellas los aspectos que más les gustaban, sino que sus preferencias se formaron de acuerdo a los significados y juicios difundidos por la industria cultural, los cuales en algunas ocasiones respondieron a los intereses comerciales de las casas anunciantes.

En el caso colombiano, pocos años antes de la llegada del cine sonoro, la industria filmica norteamericana se impuso sobre la italiana. Cambio posible, entre otras cosas, porque Estados Unidos difundió el cine como entretenimiento de masas, es decir, propagó la idea de que el público asistía más al cine para divertirse e intensificar las emociones y menos para experimentar con las cintas un goce artístico de gran complejidad o extraer una lección moral. Muestra de lo acertado de esta idea fue el éxito de las series basadas en el folletín popular, cuyas situaciones asombrosas y peligrosas fascinaron al grueso del público colombiano.

\section{Fuentes}

\section{Manuscritas}

National Archives and Records Administration, College Park (NARA)

Colombia Consular Post

Colombia Diplomatic Posts

General Records of Department of State 


\section{Periódicos y revistas}

Cine Mundial (New York) 1917-1923.

Exhibitors Herald (Chicago) 1920-1930.

Mensajero Paramount (New York) 1931.

Motion Picture News (New York) 1915.

Películas (Bogotá) 1916-1920.

The International Photographer (New York) 1930.

The Moving Picture World (New York) 1915.

West Coast Leader (Lima) 1920.

\section{Bibliografía}

Abel, Richard. Encyclopedia Early Cinema. Londres / New York: Routledge, 2005.

Arias Trujillo, Ricardo. Historia de Colombia contemporánea (1920-2010). Bogotá: Ediciones Uniandes, 2010.

Benjamin, Walter. La obra de arte en la época de su reproductibilidad técnica. México: Itaca, 2003.

Bourdieu, Pierre. El sentido social del gusto. Buenos Aires: Siglo XXI, 2010.

Canjels, Rudmer. Distributing Silent Film Serials. Local Practices, Changing Forms. Cultural Transformation. New York / Londres: Routledge, 2011.

Chartier, Roger. Cardenio entre Cervantes y Shakespeare. Historia de una obra perdida. Barcelona: Gedisa, 2012.

Concha Henao, Álvaro. Historia social del cine en Colombia. Tomo 1. Bogotá: Publicaciones Black María Escuela de Cine, 2014.

Eco, Umberto. El superhombre de masas. Bogotá: Debolsillo, 2012. - Interpretación y sobreinterpretación. Cambridge: Cambridge University Press, 1990. . Apocalípticos e integrados. Barcelona:Tusquest, 2001.

Fein, Seth. "El cine y las relaciones culturales entre México y Estados Unidos durante la década de 1930". Secuencia. Revista de historia y ciencias sociales 34 (1996): 155-196.

Gatica, Camila. "Social Practices of Modernity: Cinema-going in Buenos Aires and Santiago, 1915-1945". Tesis de doctorado en Historia, University College London, 2013.

Gunning, Tom. "The Cinema of Attraction(s): Early Film, Its Spectator and the Avant-Garde”. Early Cinema. Space, Frame, Narrative. Ed.Thomas Elsaesser. Londres: British Film Institute, 1990.

Kitamura, Hiroshi. Screening Enlightenment. Hollywood and the Cultural Reconstruction of Defeated Japan. Ithaca / Londres: Cornell University Press, 2010.

Levine, Lawrence. The Emergence of Cultural Hierarchy in America. Cambridge: Harvard University Press, 1988.

Metz, Christian. Ensayos sobre la significación en el cine (1964-1968). Volumen 1. 
Barcelona: Paidós, 2002.

Monsiváis, Carlos. ¿Cómo se dice OK en inglés?”. La americanización de la modernidad. Comp. Bolívar Echeverría. México: Era, 2008.

Nieto, Jorge y Diego Rojas. Tiempos del Olympia. Bogotá: Fundación Patrimonio Fílmico Colombiano, 1992.

Núñez, Luz Ángela. El obrero ilustrado. Prensa obrera y popular en Colombia 19091929. Bogotá: Ediciones Uniandes,2006.

Purcell, Fernando. ¡De película! Hollywood y su impacto en Chile, 1910-1950. Santiago: Taurus, 2012.

. "Una mercancía irresistible. El cine norteamericano y su impacto en Chile, 1910-1930”. Historia Crítica 38 (2009): 46-69.

Rosenberg, Emily. Spreading the American Dream. American Economic and Cultural Expansion, 1890-1945. New York: Hill and Wang, 1982.

Sadoul, Georges. "El arte mudo (1895-1930)". Historia del cine mundial. Ed. Georges Sadoul. México: Siglo XXI, 1972.

Serna, Laura. Making Cinelandia. American Films and Mexican Film Culture before the Golden Age. Durham: Duke University Press, 2014.

Tejada, Luis. Gotas de Tinta. Bogotá:Andes, 1977.

Thompson, Kristin. "The Rise and Fall of Film Europe". "Film Europe" and "Film America". Cinema, Commerce and Cultural Exchange, 1920-1939. Eds. Andrew Higson y Richard Maltby. Exeter: University of Exeter Press, 1999.

. Exporting Entertainment. American in the World Film Market, 1907-1934. Londres: BFI Publishing, 1985. 